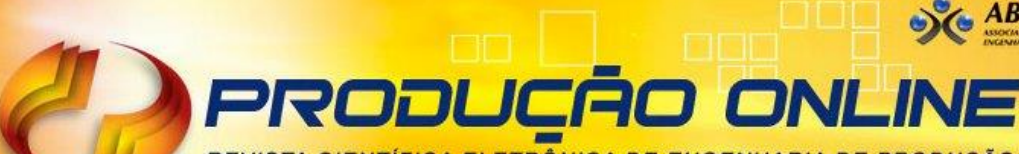 \\ REVISTA CIENTIFICA ELETRÖNICA DE ENGENHARIA DE PRODUÇÃO \\ ISSN 1676-1901
}

\section{MODELO DE DECISÃO MULTICRITÉRIO PARA ESCOLHA DO MODO DE TRANSPORTE: UM ESTUDO DO ESCOAMENTO DA PRODUÇÃO DE GRÃOS DE MATO GROSSO DO SUL}

\section{MULTICRITERIA DECISION MODEL TO CHOOSE THE MOST SUITABLE TRANSPORTATION SYSTEM: A STUDY OF THE SOYBEAN PRODUCTION FLOW IN MATO GROSSO DO SUL STATE}

\author{
Danilo Medeiros de Castro* E-mail: danilomdecastro@gmail.com \\ João Gilberto Mendes dos Reis ${ }^{* * *}$ E-mail: igilbertomreis@unip.br \\ Oduvaldo Vendrametto** E-mail: oduvaldov@uol.com.br \\ Antônio Carlos Vaz Lopes* E-mail: antoniolopes@ufgd.edu.br \\ *Universidade Federal da Grande Dourados (UFGD), Dourados, MS \\ **Universidade Paulista (UNIP), São Paulo, SP
}

Resumo: O Brasil é um dos maiores produtores de grãos do mundo. O estado de Mato Grosso do Sul (MS), por exemplo, é o terceiro maior produtor de milho e quinto maior produtor de soja do País. Entretanto, entre suas maiores dificuldades está à de estabelecer um processo logístico adequado para o transporte desses grãos. O objetivo deste artigo é apresentar um modelo de decisão multicritério para escolha do modo de transporte mais adequado para os grãos produzidos em Mato Grosso do Sul. Para condução do estudo foram entrevistados oito especialistas em logística do estado de Mato Grosso do Sul e sete representantes de empresas e instituições ligadas ao segmento logístico do agronegócio. Além disso, foi estabelecido um modelo de decisão multicritério utilizando o método da Análise Hierárquica do Processo (AHP), para determinar o modal de transporte que apresenta a melhor relação custo e benefício dos atributos físicos de transporte como: velocidade, confiabilidade, capacidade, disponibilidade e frequência. Os resultados demonstraram que o modal rodoviário apesar de possuir o custo de frete mais alto é a melhor opção para o estado de MS devido aos benefícios criados por esse sistema de transporte.

Palavras-chave: Logística. Modais de Transportes. Produção de Grãos. Mato Grosso do Sul. Análise Hierárquica do Processo.

\begin{abstract}
Brazil is one of the most important players in the world grain production. The Mato Grosso do Sul state (MS), for instance, holds the third place in corn production and fifth place in soybean production. However, its major challenge is establishing a logistic system for grain transportation. The purpose of this paper is to present a multicriteria decision model to choose the most optimal transportation system for the grains produced in MS. To perform this research, we interviewed 15 transport, commercial, and government specialists involved with state transportation systems. Moreover, we established the multicriteria decision model using the analytic hierarchy process (AHP) to determine the transportation system that presents the best relationship between cost and benefits of physical attributes of transport such as velocity, reliability, capacity, availability, and frequency. Our results showed that road freight is the best option for MS, despite road transportation systems having a higher cost, owing to the benefits created by this kind of system.
\end{abstract}

Keywords: Logistics. Transportation System. Grains Production. Mato Grosso do Sul, Analytic Hierarchy Process. 


\section{INTRODUÇÃO}

O Brasil destaca-se mundialmente na produção de grãos e está entre os maiores produtores de cereais do mundo (ARAÚJO, 2013). A produção de grãos do País projetada para 2015 é de 204,53 milhões de toneladas, sendo $83,18 \%$ soja e milho (COMPANHIA NACIONAL DE ABASTECIMENTO - CONAB, 2015). A elevada produtividade de grãos brasileira é resultado de alta tecnologia aplicada na agricultura (OSAKI e BATALHA, 2014). Entretanto, apesar dessa sua alta produtividade, a produção de grãos perde em competitividade no processo de escoamento logístico (KUSSANO e BATALHA, 2012). Atualmente cerca de $80 \%$ da produção agrícola brasileira são escoados por rodovias, enquanto que $16 \%$ são transportados por linhas férreas e apenas entre 3 a $4 \%$ são movimentados por vias fluviais interiores (ARAÚJO, 2013).

A agricultura voltada para exportação sempre desempenhou um papel central na economia brasileira, desde o açúcar, passando pelo café e atualmente com os grãos de soja e milho (HOPEWELL, 2014). Todavia a produção que começou no litoral se expandiu para o continente e a região Centro-Oeste que se tornou o grande polo produtivo agrícola brasileiro. Essa situação ocorreu devido ao preço da terra, o que reduziu os custos de produção, mas aumentou os custos logísticos.

A região Centro-Oeste com seus três estados Mato Grosso, Mato Grosso do Sul e Goiás é responsável por aproximadamente metade da produção de milho e soja do Brasil (MINISTÉRIO DA AGRICULTURA, PECUÁRIA E ABASTECIMENTO MAPA, 2014) e esses polos produtivos se encontram a distância entre 1.000 e 2.500 $\mathrm{km}$ dos dois principais portos brasileiros para escoamento de grãos, Santos no estado de São Paulo e Paranaguá no estado do Paraná.

Assim, as distâncias de transporte e baixa disponibilidade de infraestrutura diversificada tornaram a logística de grãos do país um enorme desafio. Desse modo, como escolher o modo de transporte mais adequado para escoar a produção de grãos? Gray (1982) indica que existem dois métodos para escolha do modo de transporte: o 'positivismo econômico' no qual a escolha está atrelada a custos e o 'positivismo tecnológico' no qual a escolha está ligada a aspectos físicos do transporte (como velocidade e frequência) e aspectos relacionados a volume (pericibilidade). Esse parece ser o modelo atual brasileiro em que a escolha do modal é feita com relação a disponibilidade e o preço do frete. Encalada e Duhamel (2014) estabelecem que a escolha do modo de transporte não deve se concentrar apenas no seu custo, os gerentes logísticos devem alinhá-los com as prioridades físicas dos serviços.

Nesse sentido, Leal Junior e D'Agosto (2011) desenvolveram o que denominam de 'Método de Escolha de Modal (MEM)', que considera três aspectos na escolha: características do produto, características do transporte e desempenho. Entretanto, a complexidade do método dificulta a sua utilização como um sistema de decisão gerencial. Morales et al. (2013) estabelecem que a distribuição de grãos só 
consegue ser otimizada e melhorada utilizando-se de uma rede intermodal e apresentam um modelo utilizando o porto de Santarém no estado do Pará. Apesar dos modelos propostos por Leal Junior e D'Agosto (2011) e Morales et al. (2013) permanecem a decisão em custos como preconizado por Gray (1982) a mais de 30 anos, pois as soluções propostas envolvem investimentos em infraestrutura, políticas governamentais e modelos complexos de baixa eficiência operacional.

O objetivo deste trabalho é apresentar um modelo de decisão para escolha do modal de transporte que permita considerar fatores físicos como velocidade, confiabilidade, capacidade, disponibilidade e frequência além dos custos. O modelo é desenvolvido baseando se na decisão multicritério de análise hierárquica proposto por Saaty (1980), conhecido como Análise Hierárquica do Processo.

O modelo da análise hierárquica foi feito utilizando o software Expert Choice ${ }^{\circledR}$ v.11 e os resultados proveem os benefícios de cada modal para cada fator que são comparados com os custos de utilização de cada um destes. Para exemplificação da metodologia utiliza-se a perspectiva do estado brasileiro de Mato Grosso do Sul, na região Centro-Oeste do País no qual sua principal produção de milho e soja estão concentradas na região no sudoeste do estado e são comercializados pelos portos de Paranaguá e Santos a uma distância aproximada de $1.100 \mathrm{~km}$.

\section{MODAIS DE TRANSPORTES PARA MOVIMENTAÇÃO DE GRÃOS}

O escoamento da produção depende entre outros fatores da disponibilidade do modo de transporte e sua capacidade de carga. Os modos de transporte utilizados para grãos no mundo são: rodoviário, ferroviário e hidroviário (BALLOU, 2006).

O modo ferroviário tem a vantagem de possuir preços atrativos para a movimentação de cargas em cursos longos. Porém, como a sua velocidade é baixa, é recomendado para o transporte de matérias-primas com pouco valor agregado (CHOPRA e MEINDL, 2012). Desse modo, é um sistema eficaz para o transporte de grãos com um valor reduzido de tonelada por quilômetro transportado.

O modo rodoviário é considerado adaptável devido à flexibilidade, pois são necessários baixos investimentos fixos para operações de transbordos (BOWERSOX et al., 2012). Recomendado para percursos curtos são sistemas frequentes e velozes quando comparadas às ferrovias (BALLOU, 2006). Todavia, algumas variáveis deveriam ser analisadas com cautela, pois a velocidade e os custos podem reverter-se por meio dos aumentos nos preços dos combustíveis, o que é muito comum no mercado brasileiro (REIS et al., 2013). Esse modo de transporte é o mais popular no Brasil para a movimentação de grãos devido a facilidade de acesso e confiabilidade, mesmo que tenha um valor de tonelagem por quilômetro mais alto e sofra com os problemas de infraestrutura viária.

O modo aquaviário, é um dos sistemas de transportes mais antigos da humanidade, cuja vantagem está relacionada à capacidade de acondicionamento de 
cargas volumosas, que podem ser realizados em alto mar, pela costa litorânea (cabotagem) e em rios (navegação interior) (BOWERSOX et al., 2012). Apesar das vantagens relacionadas a este modal, Ballou (2006) salienta limitações ligadas a aspectos climáticos (disponibilidade e confiabilidade), que podem ser um gargalo.

Quando se considera o transporte de vias marítimas, duas variáveis se destacam: a capacidade e a velocidade dos navios, pois se cria um trade-off entre a capacidade contenedora e a agilidade (RADMILOVIĆ et al., 2011). A participação do modal aquaviário para o transporte interior de grãos do Brasil é quase nulo, se concentrando apenas no chamado transporte marítimo que é a ligação dos portos entre dois países.

No estado de Mato Grosso do Sul a operação do modo ferroviário é realizada por uma companhia privada e divide-se em duas malhas: a Norte e a Oeste. A primeira interliga o Centro-Oeste às regiões Sul e Sudeste do País, enquanto que a segunda passa pelos estados de São Paulo e Mato Grosso do Sul, com possiblidade de adentrar em território boliviano. A rede inicia-se no Município de Mairinque/SP e passa em Campo Grande/MS onde a malha subdivide-se entre Corumbá e Ponta Porã, ambas no mesmo estado. Assim, escoam-se na referida rede produtos de minérios de ferro, soja, milho e álcool (DIAS, 2012).

Em relação ao modo rodoviário, o estado de MS apresenta como principais rodovias para o transporte de cargas a BR-163, BR-267 e a BR-262, incluindo neste caso o transporte de grãos (BRANCO et al., 2011).

Outro modo de transporte que pode ser utilizado no Mato Grosso do Sul para o escoamento da produção agrícola é o hidroviário. A hidrovia do Rio Paraná, composta também pelo rio Tietê, possui extensão de cerca de $2.400 \mathrm{Km}$, atendendo dividindo diversos estados da federação como Goiás, Minas Gerais, Mato Grosso do Sul, Paraná e São Paulo (BRANCO et al., 2011).

Destaca-se também a Hidrovia do Rio Paraguai, dividida em dois trechos, Cáceres, MT e Corumbá, MS a Porto Murtinho, MS; a primeira seção pode transportar cargas de até 4.000 mil toneladas e a segunda seção pode movimentar barcaças com até 25.000 toneladas. É também uma importante área de comércio entre os países do Mercado Comum do Sul - MERCOSUL, interligando os estados de Mato Grosso e Mato Grosso do Sul países como Bolívia, Paraguai, Argentina e Uruguai (BRANCO et al., 2011, DIAS, 2012).

O grande problema das hidrovias sul-mato-grossenses se refere a impossibilidade de realização do transporte de grãos sem o uso da intermodalidade, ou seja, sem a conexão com o modal rodoviário.

\section{ANÁLISE HIERÁRQUICA DO PROCESSO}

A Análise Hierárquica do Processo, mas conhecida em seu termo em inglês Analytic Hierarchy Process ou simplesmente AHP, corresponde a uma metodologia de tomada de decisão em que o problema é estruturado em hierarquias compostas 
de um objetivo, critérios e subcritérios, além das respectivas alternativas (SAATY, 1987; SAATY, 1990). Assim, deve-se organizá-lo em hierarquia, uma vez que auxilia nas questões ou atributos dos problemas, identificando-se os decisores que participam do processo, investigando-se o desenvolvimento do problema em detalhes (SAATY, 1990).

Para realizar o processo de tomada de decisão deve-se fornecer prioridades e, para isso, é necessário primordialmente entender os problemas a serem pesquisados (SAATY, 2008). A aplicação da AHP pode ser resumida em três passos de acordo com as observações de Talib e Rahman (2015) e Solimanpur et al. (2015).

O primeiro passo consiste em se elaborar a árvore hierárquica com o objetivo proposto, os critérios e os respectivos elementos dependentes desses, bem como as alternativas elaboradas, conforme Figura 1.

Figura 1 - Níveis Hierárquicos do Método AHP

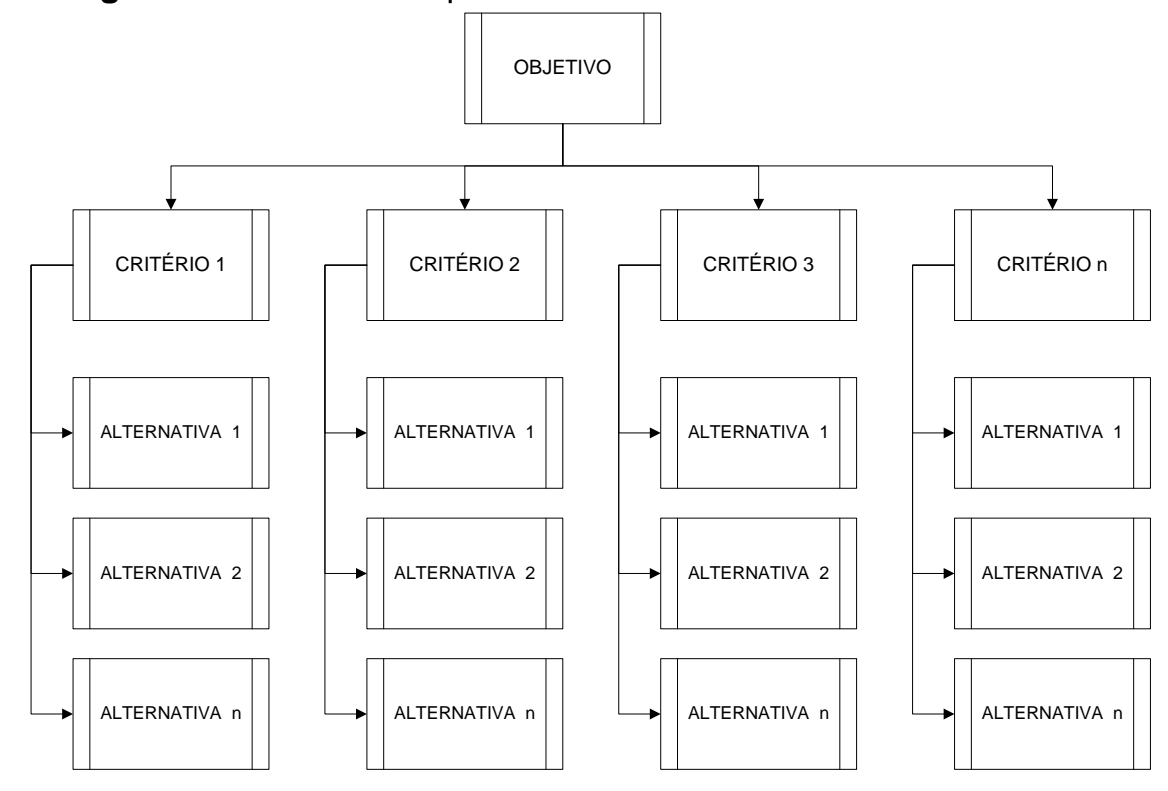

O segundo passo são comparações paritárias de cada um dos elementos do nível hierárquico, ou seja, formam-se matrizes que o auxiliam no processo de escolha, enquanto, por meio de uma escala já estabelecida, aponta as alternativas que considera mais importante proporcionando pesos específicos a essas (SAATY, 2008), conforme Tabela 1.

A Tabela 1 revela que a intensidade 1 refere-se a duas alternativas que auxiliam de maneira igualitária a julgar o objetivo do que está sendo proposto, a 3 mostra que os conhecimentos do julgador atribuem uma importância pequena de uma atividade em relação à outra e assim sucessivamente (SAATY, 2008). A Escala Fundamental auxilia o tomador de decisão a fornecer os pesos para cada par analisado, seja entre os critérios ou entre as alternativas (GOMES et al., 2004). 
Tabela 1 - Escala relativa para comparação paritária

\begin{tabular}{cc}
\hline Escala & Definição \\
\hline 1 & Igual importância \\
3 & Importância pequena \\
5 & Importância grande \\
7 & Importância muito grande \\
9 & Importância absoluta \\
$2,4,6,8$ & Valores intermediários \\
\hline
\end{tabular}

Fonte: Adaptado de Saaty (2008)

Desse modo a matriz envolve a avaliação de cada alternativa em relação ao critério de decisão, em que a matriz consiste em $n$ critérios e $m$ alternativas (SOLIMANPUR et al., 2015), equação (1).

$$
a=\left[\begin{array}{cccc}
a_{11} & a_{12} & \cdots & a_{1 n} \\
a_{21} & a_{22} & \cdots & a_{2 n} \\
\vdots & \vdots & \vdots & \vdots \\
a_{m 1} & a_{m 2} & \cdots & a_{m n}
\end{array}\right]
$$

Realizada a comparação paritária a terceira etapa consiste em verificar a consistência do julgamento dos decisores (GOMES et al., 2004). A equação (2) apresenta a razão de consistência.

$$
R C=\frac{I C}{I R}
$$

Onde:

$R C=$ corresponde à razão de consistência das respostas dos decisores.

$I C=$ representa 0 índice de consistência.

$I R$ = corresponde ao índice aleatório, que foi calculado para matrizes quadradas de ordem $n$ pelo Laboratório Nacional Oak Ridge, Estados Unidos (Gomes et al., 2004).

A Tabela 2 apresenta os valores IR para as matrizes quadradas de ordem $n$ segundo do Laboratório Nacional Oak Ridge.

Tabela 2 - Valores de IR para as matrizes quadradas de ordem n.

\begin{tabular}{ccccccc}
\hline $\mathbf{n}$ & $\mathbf{2}$ & $\mathbf{3}$ & $\mathbf{4}$ & $\mathbf{5}$ & $\mathbf{6}$ & $\mathbf{7}$ \\
\hline $\mathrm{IR}$ & 0,0 & 0,58 & 0,90 & 1,12 & 1,24 & 1,32 \\
\hline
\end{tabular}

Fonte: Adaptado de Saaty (2008)

Por meio da Tabela 2, pode-se inferir que quanto maior for a razão, maior será também a inconsistências das respostas dos decisores. Nota-se que quando a

Revista Produção Online, Florianópolis, SC, v. 16, n. 4, p. 1214-1236, out./dez. 2016. 
matriz for de ordem 2, o IR é nulo; matrizes cuja ordem for 3, o RC deve ser menor que 0,05 , para $n=4$, menor que 0,09 . Geralmente consideram-se como repostas consistentes aquelas que não ultrapassarem o índice de 0,10 ou $10 \%$, quando as ordens das matrizes forem maiores do que 4. Portanto, o processo do AHP necessita de alguns elementos fundamentais como conjunto de critérios e alternativas, comparação par a par de elementos para apresentar qual alternativa é mais preferível que outra e, assim, fornecer pesos de acordo com os conhecimentos subjetivos do tomador de decisão.

\section{METODOLOGIA}

O presente estudo teve como referência o estado de Mato Grosso do Sul (MS), que possui 79 municípios com uma população de quase 3 milhões de habitantes em pouco mais de $357 \mathrm{mil} \mathrm{km}^{2}$. A produção do estado é essencialmente agrícola, baseada nas culturas de milho, soja e cana-de-açúcar e se encontram a distâncias médias de $1.100 \mathrm{~km}$ dos dois principais portos de escoamento de grãos brasileiros: Santos e Paranaguá.

Os procedimentos metodológicos para elaboração do presente artigo foram divididos em algumas etapas de execução, Figura 2.

\subsection{Pré-identificação}

O estado de Mato Grosso do Sul possui os principais modais existentes: rodoviário, ferroviário, hidroviário, aeroviário e dutoviário. Entretanto, atualmente para o escoamento da produção agrícola os modos que podem ser utilizados são apenas o rodoviário, ferroviário e o hidroviário.

Assim, selecionaram-se várias empresas ligadas a logística de escoamento de grãos no estado de Mato Grosso do Sul, primeiramente, buscando se empresas transportadoras rodoviárias nas cidades de Corumbá, Campo Grande, Dourados, Três Lagoas e Chapadão do Sul devido a sua relação com o agronegócio. Também se identificou empresas ligadas ao segmento hidroviário em Corumbá e Três Lagoas, bem como, ferroviário que se concentra em Campo Grande. 
Figura 2 - Metodologia para a execução do modelo da pesquisa

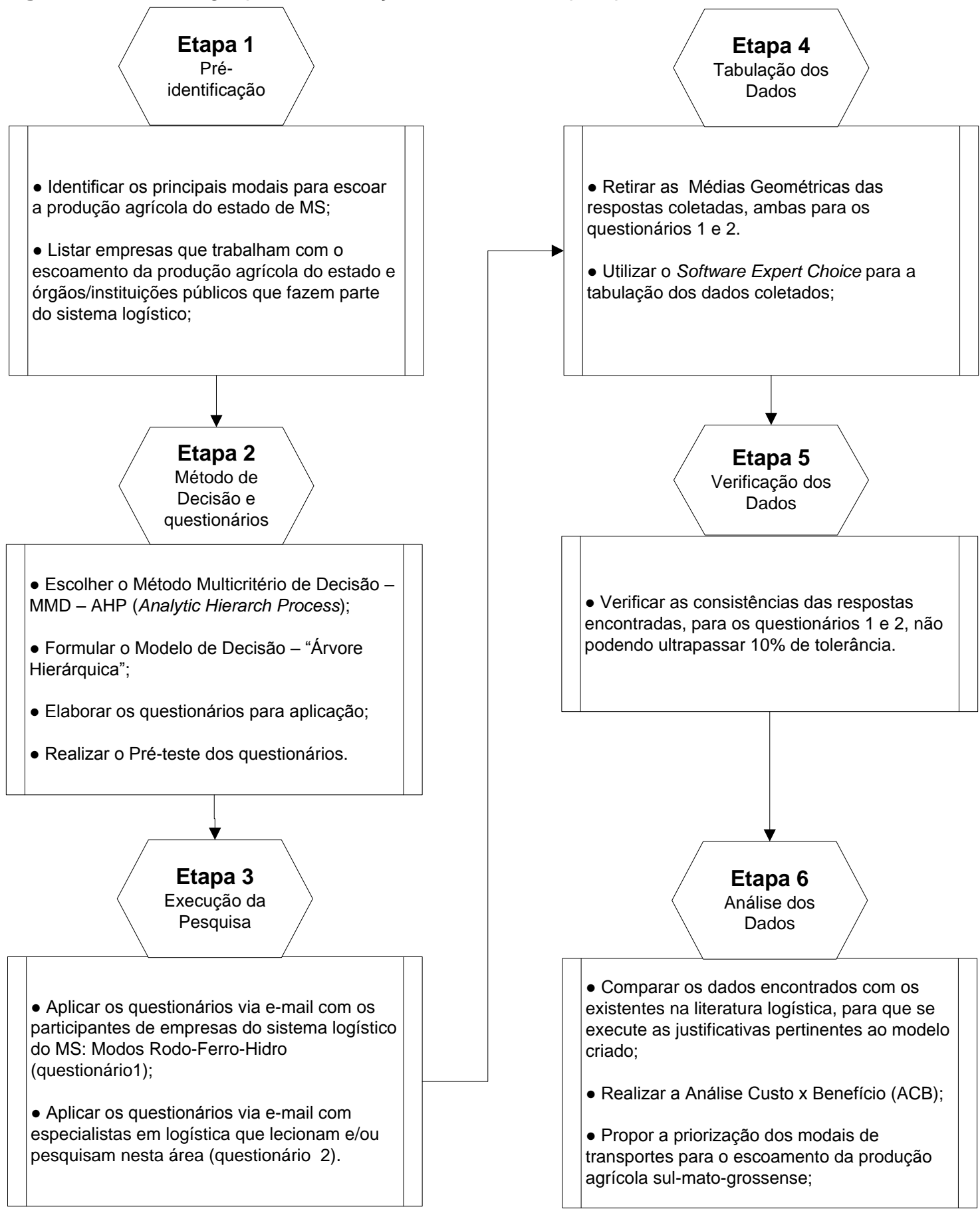

\subsection{Métodos de decisão e questionários}

$\mathrm{Na}$ literatura encontram-se inúmeros métodos multicritérios de tomada de decisão, estes estão divididos em algumas escolas como a americana que inclui a Teoria da Utilidade Multiatributo e o Método de Análise Hierárquica - AHP, a escola francesa que inclui o Método Electre I, II, III, IV e TRI e o Método Prométhé I II e V e

Revista Produção Online, Florianópolis, SC, v. 16, n. 4, p. 1214-1236, out./dez. 2016. 
a escola brasileira, cujo método de destaque é representado pelo Todim (GOMES et al., 2004).

Optou-se, nesta pesquisa, pelo Método AHP por considerar a experiência, intuição e a subjetividade dos tomadores de decisões nos momentos de escolhas, bem como, proporcionar os julgamentos em grupo (SAATY, 2008). Após a escolha do método a ser usado, recorreu-se à literatura de logística (BOWERSOX e CLOSS, 2004; LEAL JUNIOR e D'AGOSTO, 2011) para o arranjo das principais variáveis existentes.

Assim, com base nestes autores citados, as variáveis operacionais encontradas foram velocidade, confiabilidade, frequência, disponibilidade e capacidade. Os custos se mostram importante para a logística de grãos, todavia, pelo método AHP não se pode trabalhá-los como equivalente as variáveis operacionais, pois estes devem ser calculados separadamente e realizar a Análise do Custo versus Benefício (ACB) (SAATY, 1980).

Após a escolha das variáveis elaborou-se a árvore de decisão, uma das premissas do método AHP, a Figura 3 apresenta o problema hierárquico com as respectivas variáveis.

Nesta etapa foram elaborados os questionários com perguntas abertas sobre a identificação do indivíduo e da empresa/instituição que atua, experiências no setor e aspectos sobre a intuição e subjetividade na tomada de decisão. Além disso, utilizaram-se perguntas fechadas relacionadas à comparação par a par de cada variável em relação ao peso que o indivíduo escolheria de acordo com a opinião do mesmo na área de atuação. Estes questionários passaram por pré-testes para a validação do processo de decisão.

Figura 3 - Modelo de decisão formulado na estrutura hierárquica

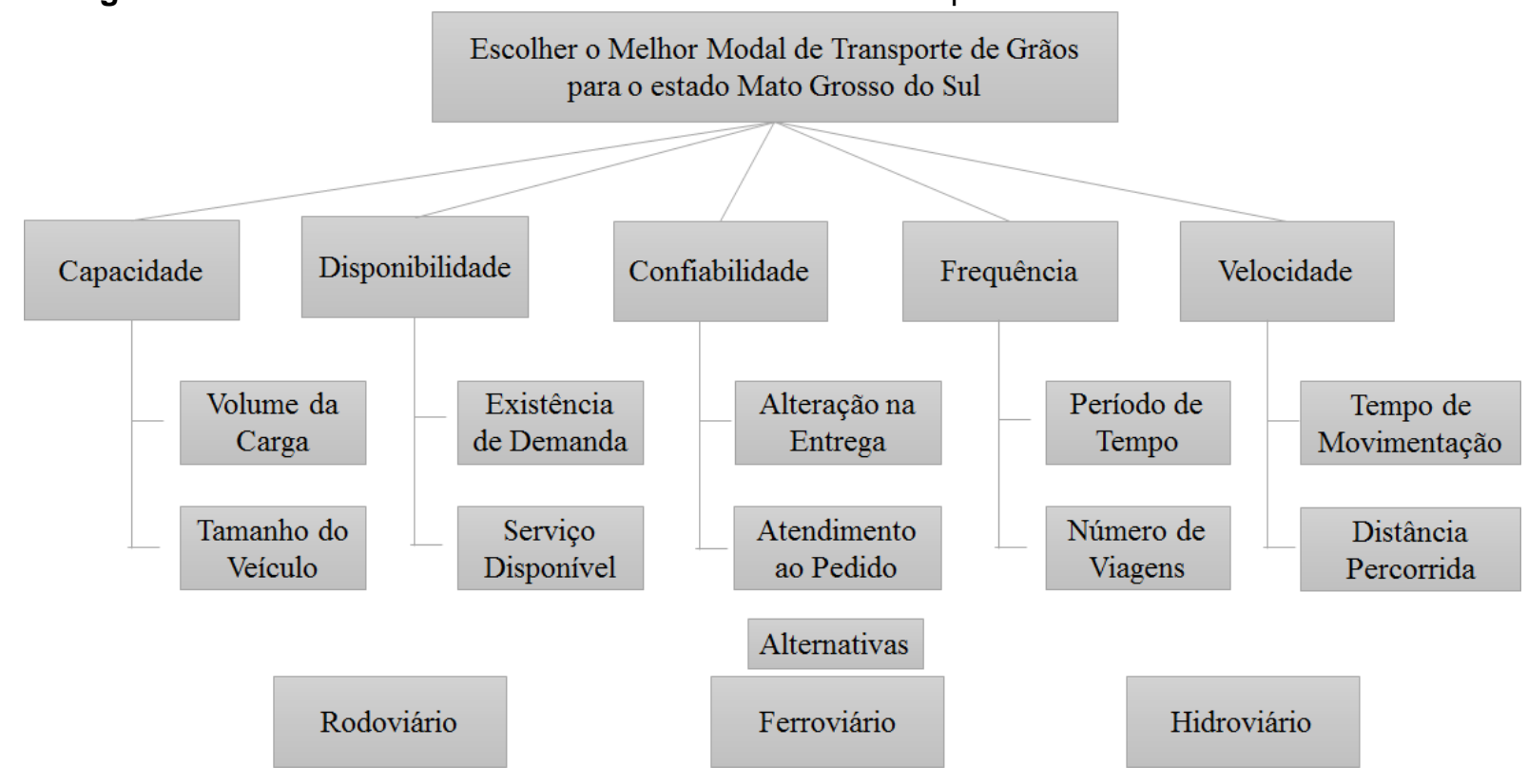




\subsection{Execução da pesquisa}

Em relação às escolhas das empresas e instituições que poderiam participar das entrevistas, selecionou-se grupos de empresas, órgãos governamentais e especialistas que lecionam e pesquisam nesta área. Foram primordialmente realizados contatos telefônicos e para aqueles que optaram pela participação na pesquisa, foram enviados questionários via e-mail para que pudessem respondê-los. Neste sentido, a pesquisa conteve um total de quinze participantes que envolveram:

- Oito especialistas em logística do estado de Mato Grosso do Sul;

- Sete representantes de empresas e instituições ligadas ao segmento logístico do agronegócio, que incluem três transportadoras rodoviárias que foram chamadas de Transportadoras "A", "B" e "C", duas instituições federais ligadas ao modal ferroviário (Agência Nacional de Transportes Terrestres - ANTT / Superintendência de Transportes Ferroviários de Cargas e a VALEC - Empresa de Engenharia, Ferrovia e Construções S.A.), a Administradora da Hidrovia do Rio Paraná - AHRANA e a ANTT, posto rodoviário de Dourados-MS).

A pesquisa foi realizada no segundo semestre de 2014 utilizando dois questionários, no primeiro consiste em perguntas para os especialistas em logística. Os especialistas responderam às perguntas referentes à comparação para a par das alternativas (Modos Ferroviário, Hidroviário e Rodoviário) em relação aos subcritérios (Ferroviário, Hidroviário e Rodoviário). Estes realizaram a comparação par a par dos subcritérios (Tamanho do Veículo, Volume da Carga, Existência de Demanda, Serviço Disponível, Alterações nas Entregas, Atendimento ao Pedido, Período de Tempo, Número de Viagens, Tempo de Movimentação e Distância Percorrida).

Analogamente, o segundo questionário contém perguntas direcionadas a especialistas das empresas que realizaram a comparação par a par dos subcritérios (Tamanho do Veículo, Volume da Carga, Existência de Demanda, Serviço Disponível, Alterações nas Entregas, Atendimento ao Pedido, Período de Tempo, Número de Viagens, Tempo de Movimentação e Distância Percorrida) em relação aos critérios (Capacidade, Disponibilidade, Confiabilidade, Frequência e Velocidade).

\subsection{Tabulação dos dados}

Esta pesquisa trata-se de uma tomada de decisão em grupo formado por indivíduos com interesses distintos dentro do sistema logístico, neste aspecto, a coleta de dados foi realizada de forma individual e posteriormente, utilizaram-se as médias geométricas para a convergência dos dados. 
Neste sentido, quando se decide utilizar o Método AHP para tomada de decisão em grupo com divergências de opiniões, recomenda-se primeiramente a coleta dos pesos individuais e em seguida, calculam-se as médias geométricas como se fosse um único valor (DYER e FORMAN, 1992, BASAK e SAATY, 1993, ISHIZAKA e LABIB, 2011). A equação (3) representa a média geométrica utilizada:

$$
\left(\prod_{i=1}^{n} a_{i}\right)=\sqrt[n]{a_{1} a_{2} \ldots a_{n}}
$$

Onde:

$\mathrm{n}=$ quantidade de respondentes

a1, a2, ....an = igual resposta de cada respondente

A média geométrica é calculada para cada peso a ser atribuído. Após o cálculo da média geométrica das respostas dos entrevistados, foi utilizado o Software Expert Choice $\AA^{\circledR}$ v. 11 para os cálculos dos pesos médios a partir dos pesos individuais de cada respondente. Assim, foi possível a tomada de decisão em grupo com divergências de opiniões e interesses próprios inseridos na cadeia logística de grãos.

\subsection{Verificação dos dados}

Realizada as ponderações, foi calculada a razão de consistência das respostas gerais, ou seja, averiguado se as respostas estavam dentro do limite de $10 \%$ que é recomendado para do método AHP, seguindo a Equação 2 e a Tabela 2.

Os dados mantiveram uma inconsistência abaixo de 0,10 não sendo necessário uma adequação das informações inseridas no modelo de decisão.

\subsection{Análise dos dados}

Para a análise dos dados comparou-se as variáveis operacionais obtidas por meio da pesquisa com a revisão para averiguar se as respostas obtidas estão de acordo com o encontrado na literatura, a priorização da escolha dos modos de transportes necessita-se também incluir os custos de fretes, pois cada modo possui custos específicos para distâncias e produtos singulares.

Fez-se necessário a Análise Custo-Benefício (ACB) proposta por Saaty (1980) para comparar os benefícios alcançados a partir das variáveis encontradas na árvore de decisão do método AHP em relação aos custos de fretes existentes no mercado para granéis sólidos agrícolas. $O$ fator distância também influência nos custos de frete, com esta premissa, assume-se o custo do volume transportado em função da quilometragem por modal de transporte, ou seja, tonelada por km. 


\section{RESULTADOS E DISCUSSÕES}

\subsection{Resultado geral}

A Figura 4 apresenta o resultado da priorização dos modais de transportes obtidos pelo método AHP.

Figura 4 - Priorização dos modais de transportes considerando a convergência dos critérios

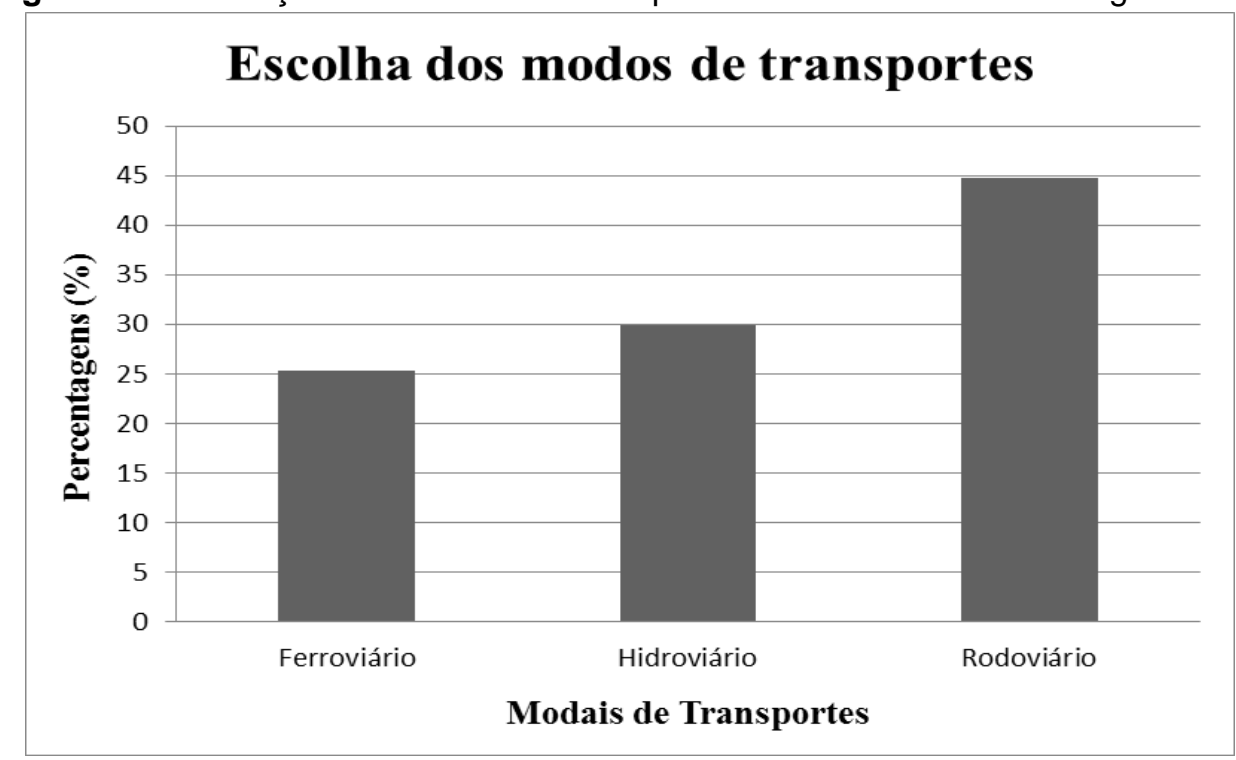

O modelo de decisão indicou que considerando os diversos critérios e subcritérios e as ponderações das opiniões dos envolvidos na pesquisa demonstram que o melhor sistema de transporte para escoamento de grãos em Mato Grosso do Sul é o rodoviário $(0,488)$, seguido do hidroviário $(0,299)$ e, por último, o ferroviário $(0,253)$.

Esse resultado é um tanto contrastante com as pesquisas apresentadas que indicam que o transporte rodoviário é o mais ineficiente dos três. Entretanto, é preciso enfatizar que essas pesquisas consideram o critério capacidade e custo por tonelada-quilômetro, enquanto o modelo de decisão multicritério considera cinco variáveis, sendo o custo utilizado para realizar apenas a relação custo-benefício.

Neste sentido, as rodovias iniciaram-se com a ideia de um sistema de transporte confiável, ágil e com poucas empresas concorrentes e descentralizadas. A partir disso, o diferencial do modo rodoviário em relação aos outros está justamente na maior flexibilidade de entrega dos produtos, e evita-se processos de transbordos e, por consequência, os custos de frete tornam-se baixos devido à unimodalidade.

Pelos resultados observa-se a importância do modal rodoviário, visto que investimentos neste modo se tornam essenciais, sobretudo, em relação às concessões privadas que podem fornecer serviços com maior desempenho quando comparadas ao setor público. 
Nota-se que pela priorização encontrada pelo método AHP que o modal rodoviário despontou como o que maximiza as variáveis operacionais; esta realidade ocorre pela maior confiabilidade que este modo possui, com facilidades de entregas "porta a porta". Além disso, o processo de escolha dos modos de transportes pode ser influenciado por diversas variáveis; dentre estas se destacam os critérios operacionais como capacidade, disponibilidade, confiabilidade, frequência e velocidade. Os resultados do impacto das variáveis na decisão podem ser observados na Tabela 3.

Tabela 3 - Resultado geral do modelo baseado na média geométrica da opinião dos entrevistados

\begin{tabular}{cccccc}
\hline & \multicolumn{5}{c}{ Critérios } \\
\cline { 2 - 6 } Modal & Capacidade & Disponibilidade & Confiabilidade & Frequência & Confiabilidade \\
\hline Ferroviário & 0,256 & 0,232 & 0,174 & 0,297 & 0,174 \\
Hidroviário & 0,659 & 0,095 & 0,087 & 0,151 & 0,087 \\
Rodoviário & 0,085 & 0,673 & 0,739 & 0,552 & 0,739 \\
\hline
\end{tabular}

\subsection{Capacidade}

O modo hidroviário, no que tange à capacidade, Figura 5 , se mostrou como a melhor decisão com base no modelo multicritério, considerando as variáveis tamanho do veículo e volume de carga $(0,659)$. O critério capacidade torna-se importante para o escoamento de produtos. De acordo com Bowersox e Closs (2004) o modal hidroviário é considerado como o mais viável quando se busca pelo critério capacidade, seguidos pelos modos ferroviário e rodoviário, respectivamente.

Figura 5 - Priorização dos modais de transportes para o critério capacidade

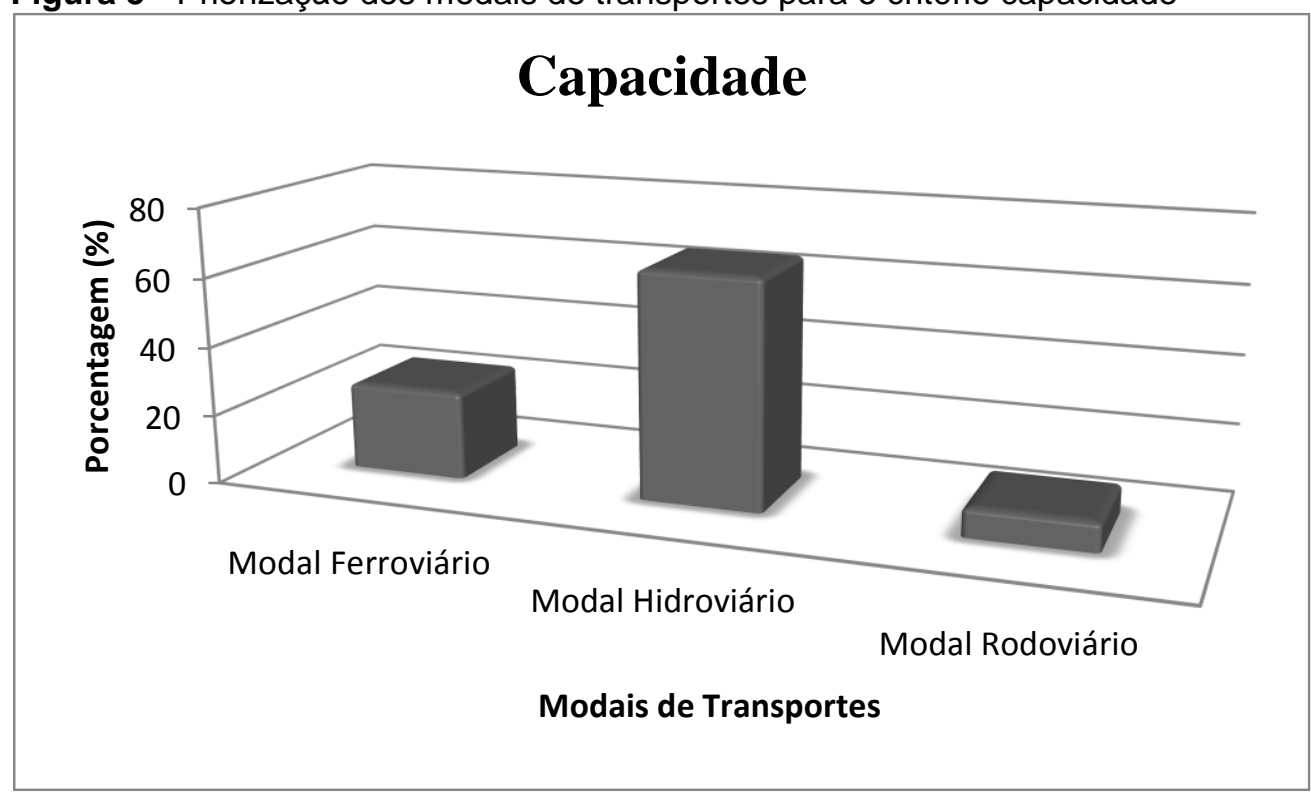

Revista Produção Online, Florianópolis, SC, v. 16, n. 4, p. 1214-1236, out./dez. 2016. 
O critério capacidade torna-se importante para o escoamento de produtos, de acordo com Reis (2014), existem situações de demanda elevada em que o transporte não pode ser executado pela falta de caminhões e trens, o que força a necessidade de armazenagem até que se regule a oferta de veículos. Neste sentido, a capacidade ainda pode ser influenciada pela quantidade de operadores logísticos existentes para auxílio da execução do transporte e na maneira em que se realizam os processos de transbordo.

Segundo Prater et al. (2013), o transporte de grãos a longas distâncias por meio de barcaças se mostram mais eficientes em relação ao critério capacidade e pela maior contenção, o que reduz os custos fixos existentes no transporte. Souza e Markoski (2013) argumentam que o modal rodoviário apresenta a desvantagem de possuir pouca capacidade quando comparados com os modos hidroviário e ferroviário.

O modo ferroviário apresenta benefício quando comparado ao sistema rodoviário, justamente pela maior capacidade de transporte, além de preferências por parte das transportadoras ferroviárias por clientes menores de modo que 0 transporte ocorra no momento exigido pela demanda (KUSSANO e BATALHA, 2012).

Pode-se entender que o modal hidroviário é o mais significativo quando se considera o critério capacidade em relação aos outros modos de transportes ferroviário e hidroviário. A presente pesquisa aponta convergência das respostas dos participantes entrevistados em relação a autores encontrados na literatura sobre logística e confirma-se o quanto este sistema de transporte pode ser representativo para a capacidade.

\subsection{Disponibilidade}

Em relação a disponibilidade, Figura 6 , os resultados demonstraram que 0 modo rodoviário corresponde ao mais disponível no modelo de decisão considerando as variáveis 'existência de demanda' e 'serviço disponível' $(0,673)$.

Segundo Souza e Markoski (2013), o modal ferroviário mostra-se eficaz para distâncias longas, porém, este modo de transporte tem como empecilho a baixa disponibilidade no território brasileiro, pois depende de linhas férreas para a utilização deste sistema.

A disponibilidade está ligada a ideia de flexibilidade, assim, os sistemas de transportes podem estar vulneráveis a interrupções, situações sem previsões como problemas nas demandas são comuns (REIS, 2014). Dullaert e Zamparini (2013) destacam que o papel da disponibilidade pode relacionar-se com o tempo que um produto permanece em trânsito até que chegue ao destino esperado. 
Figura 6 - Priorização dos modais de transportes para o critério disponibilidade

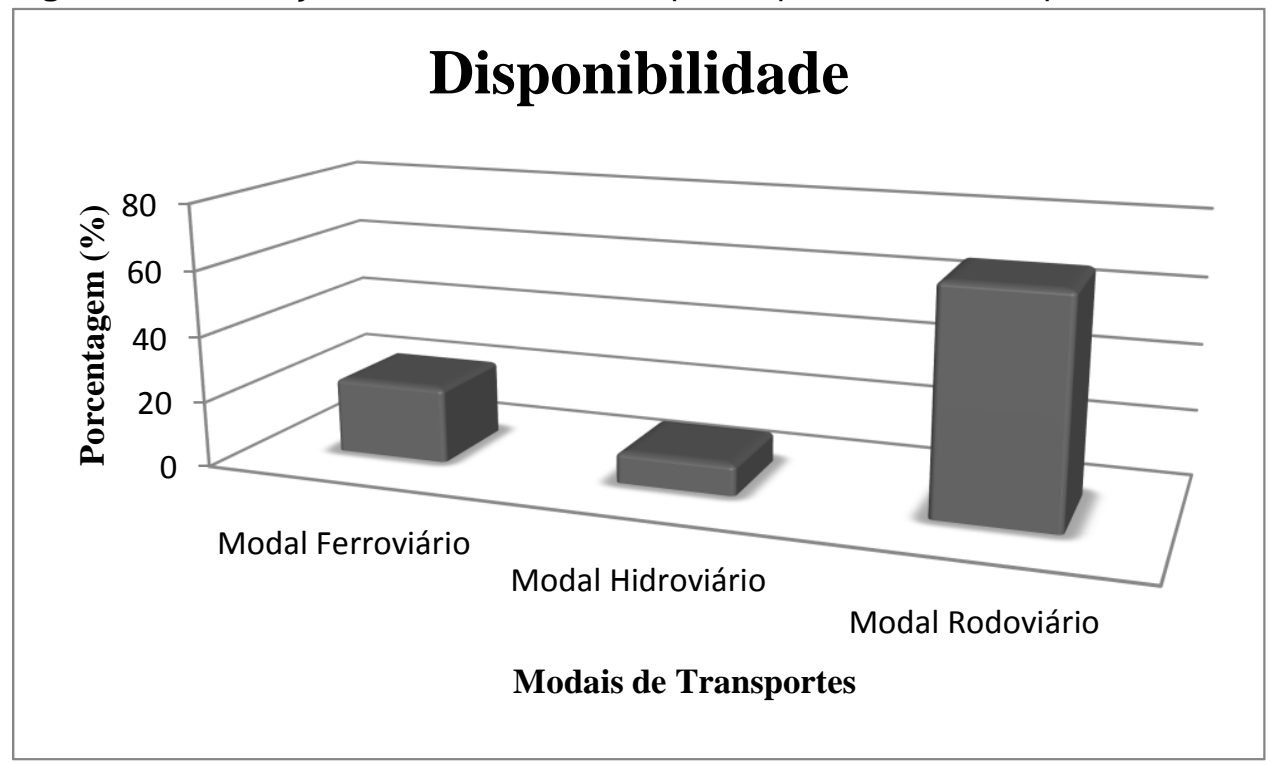

A partir do exposto, o modo hidroviário pode ser considerado o sistema de transportes com menor grau de disponibilidade, pois depende das condições geográficas de rios e tal fato está diretamente ligado a este caso. Investimentos nas hidrovias também são necessárias para tornar este modal também disponível aos usuários interessados.

\subsection{Confiabilidade}

O critério confiabilidade, Figura 7, apresentou o modo rodoviário como a melhor opção $(0,739)$ para o transporte de grãos. Este resultado condiz com a literatura sobre confiabilidade, na qual o sistema rodoviário é considerado confiável por parte dos usuários.

Figura 7 - Priorização dos modais de transportes para o critério confiabilidade

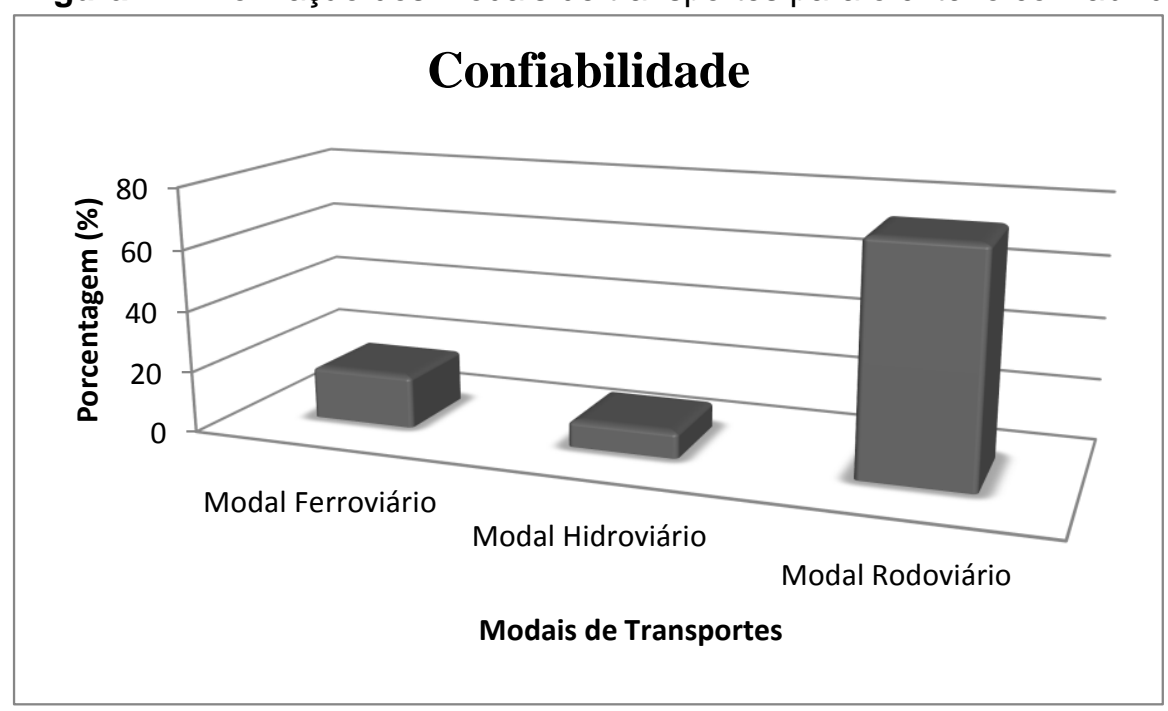

Revista Produção Online, Florianópolis, SC, v. 16, n. 4, p. 1214-1236, out./dez. 2016. 
Um modal pode ser confiável quando o mesmo não suporta alternâncias nos processos de entrega do bem e/ou prestação de serviço à demanda. Nesse caso as interferências que podem ocorrer nas vias férreas e hidroviárias causam maiores impactos na confiabilidade de entrega do que ocorre no rodoviário que pode se utilizar de vias alternativas para chegar ao destino final.

A confiabilidade do sistema rodoviário é considerada elevada por parte dos usuários, pois este modo de transporte é efetivo devido à possibilidade de chegar-se de um ponto a outro com facilidade, sem percalços (REIS et al., 2013). Um modal pode ser confiável quando o mesmo não suporta alternâncias nos processos de entrega do bem e/ou prestação de serviço à demanda, ou seja, sofrem poucas influencias de agentes externos (BOWERSOX e CLOSS, 2004).

\subsection{Frequência}

No critério frequência, Figura 8 , o modo rodoviário também foi o mais relevante $(0,552)$. A frequência pode ser entendida como as vezes em que o sistema de transporte foi operado em relação ao período de tempo deste processo. Este critério pode também ser entendido como o número de vezes que um modal realizou uma viagem a partir do ponto (origem/destino).

Figura 8 - Priorização dos modais de transportes para o critério frequência

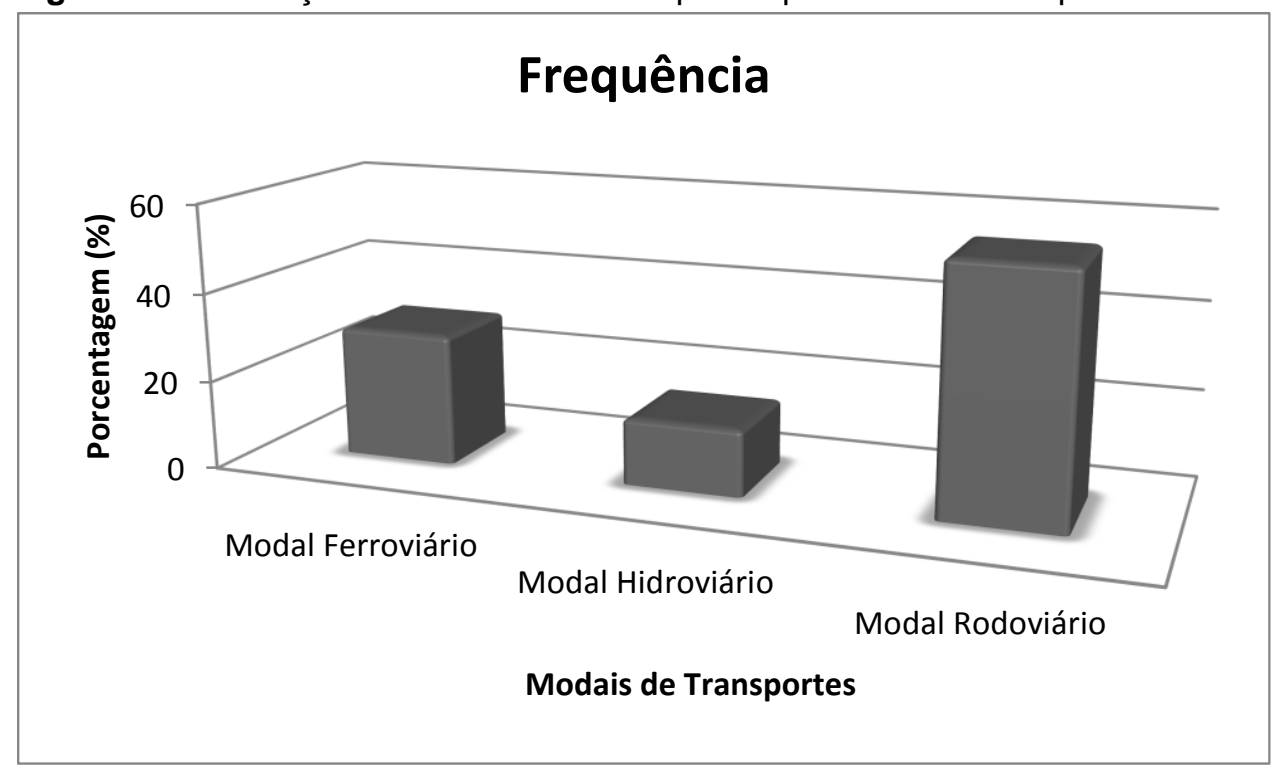

De acordo com Fleury (2002), a frequência pode ser entendida como às vezes em que o sistema de transporte foi operado em relação ao período de tempo deste processo. Este critério pode também ser entendido como o número de vezes que um modal realizou uma viagem a partir do ponto (origem/destino) estabelecido (BOWERSOX e CLOSS, 2004, BALLOU, 2006). 
Nesse sentido o modo rodoviário corresponde ao modo com maior frequência quando comparado com os outros sistemas, visto que executa mais viagens com período de tempo menor quando comparado aos sistemas ferroviário e hidroviário.

\subsection{Velocidade}

No critério velocidade, Figura 8, o modelo apresenta uma proximidade entre os valores com predominância ao sistema hidroviário $(0,393)$. Os especialistas consideraram o modal hidroviário mais veloz do que o ferroviário e rodoviário.

Figura 8 - Priorização dos modais de transportes para o critério confiabilidade

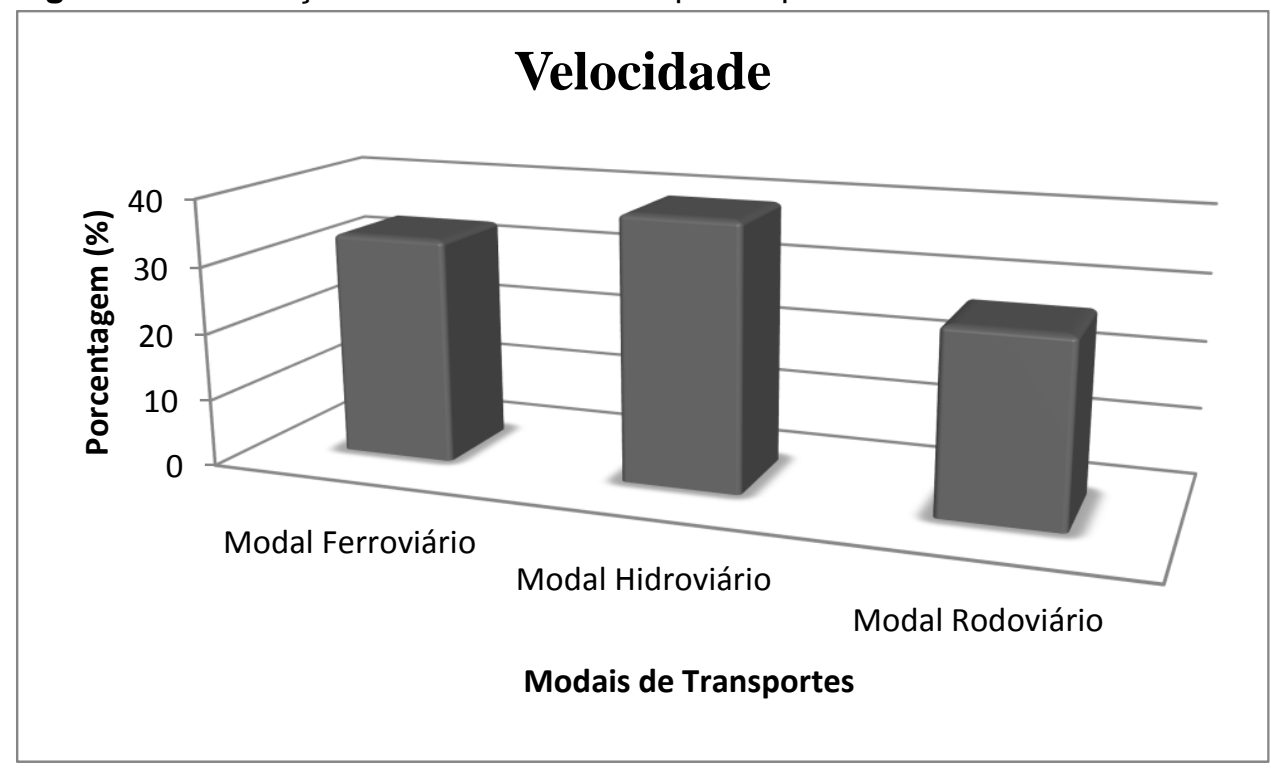

Reis et al. (2013) argumentam que a velocidade do modal rodoviário é mais eficiente para transporte de produtos a distâncias curtas e médias, enquanto que para distâncias longas outros sistemas de transportes deveriam ser utilizados. Estes relatam que aspectos sobre velocidade precisam ser constantemente monitorados, sobretudo em relação ao modo rodoviário que sobre a influência de congestionamentos.

Os entrevistados consideraram o modal hidroviário mais veloz do que o ferroviário e rodoviário, entretanto, Souza e Markoski (2013) apresentam justamente o oposto, ou seja, demonstram que a desvantagem do modal hidroviário está ligada a menor velocidade em relação aos outros modos. 


\subsection{Análise do custo versus benefícios}

O frete hidroviário custa aproximadamente $20 \%$ do custo do modal rodoviário e cerca de $70 \%$ do modo ferroviário, pois estes valores significativos são utilizados pelos transportadores dos dois sistemas, para que haja atração às demandas pela redução do custo de frete. A Tabela 4 apresenta os custos de frete para os modais rodoviário, ferroviário e o hidroviário por tonelada transportada de grãos por quilômetro.

Tabela 4 - Custo de frete $(\mathrm{R} \$)$ por tonelada (t) por quilômetro $(\mathrm{km})$

\begin{tabular}{|c|c|c|c|c|c|}
\hline \multicolumn{6}{|c|}{ Frete por Modal de Transporte } \\
\hline $\begin{array}{c}\text { Modal } \\
\text { Rodoviário }\end{array}$ & Até 200 km & $\begin{array}{c}\text { Entre } 200 \mathrm{e} \\
500 \mathrm{~km}\end{array}$ & $\begin{array}{c}\text { Entre } 500 \mathrm{e} \\
800 \mathrm{~km}\end{array}$ & $\begin{array}{c}\text { Entre } 800 \mathrm{e} \\
1100 \mathrm{~km}\end{array}$ & $\begin{array}{l}\text { Acima de } \\
1100 \mathrm{~km}\end{array}$ \\
\hline $\begin{array}{c}\text { Frete }(\mathrm{R} \$ / \mathrm{t} . \mathrm{km}) \\
\text { Modal } \\
\text { Ferroviário }\end{array}$ & $\begin{array}{c}0,174 \\
A L L-M^{*} \\
\text { Até } 500 \mathrm{~km}\end{array}$ & $\begin{array}{c}0,131 \\
A L L-M N \\
\text { Acima de } 500 \\
\text { km }\end{array}$ & $\begin{array}{c}0,114 \\
A L L-\mathrm{MO}^{* *} \\
\text { Até } 500 \mathrm{~km}\end{array}$ & $\begin{array}{c}0,102 \\
\text { ALL }-\mathrm{MO} \\
\text { Acima de } 500 \\
\mathrm{~km}\end{array}$ & 0,088 \\
\hline Frete $(\mathrm{R} \$ / \mathrm{t} . \mathrm{km})$ & 0,098 & 0,067 & 0,073 & 0,068 & \\
\hline $\begin{array}{c}\text { Modal } \\
\text { Hidroviário }\end{array}$ & \multicolumn{2}{|c|}{ Até $1000 \mathrm{~km}$} & \multicolumn{2}{|c|}{ Acima de $1000 \mathrm{~km}$} & \\
\hline Frete $(\mathrm{R} \$ / \mathrm{t} . \mathrm{km})$ & \multicolumn{2}{|c|}{0,056} & \multicolumn{2}{|c|}{0,020} & \\
\hline
\end{tabular}

Os valores escolhidos para a composição da Tabela 4 foram aqueles acima de $1.100 \mathrm{~km}$ para o modo rodoviário, ALL - Malha Oeste acima de $500 \mathrm{~km}$ para o modal ferroviário e o acima de $1.000 \mathrm{~km}$ para o frete do sistema hidroviário. Estes valores de custos por tonelada-quilômetro foram priorizados levando em consideração a posição geográfica do estado de Mato Grosso do Sul até os principais portos com a finalidade de exportação de grãos.

Esses valores foram normalizados para efeito de comparação entre o custo $e$ - benefício gerado entre a variável capacidade, disponibilidade, confiabilidade, frequência e velocidade. A Tabela 5 mostra a normalização dos dados do custo de frete e o benefício encontrado pelo método AHP.

Tabela 5 - Normalizações dos dados de custo de frete versus benefício gerado

\begin{tabular}{cccc}
\hline $\begin{array}{c}\text { Modal de } \\
\text { Transporte }\end{array}$ & $\begin{array}{c}\text { Custo de Frete } \\
(\mathbf{R} \mathbf{\text { t.km}})\end{array}$ & $\begin{array}{c}\text { Índice Normalizado do } \\
\text { Frete (\%) }\end{array}$ & $\begin{array}{c}\text { Benefício Gerado } \\
\text { pelo AHP (\%) }\end{array}$ \\
\hline Ferroviário & 0,068 & 0,368 & 0,253 \\
Hidroviário & 0,020 & 0,114 & 0,299 \\
Rodoviário & 0,088 & 0,500 & 0,488 \\
& 0,176 & 1,000 & 1,000 \\
\hline
\end{tabular}


A partir da Tabela 5, pode-se executar a comparação do índice normalizado do custo de frete em relação aos benefícios encontrados pela priorização do modo de transporte, conforme pode ser visualizado na Figura 9.

Figura 9 - Análise do custo versus benefício para a priorização do modo de transporte da produção de grãos de Mato Grosso do Sul

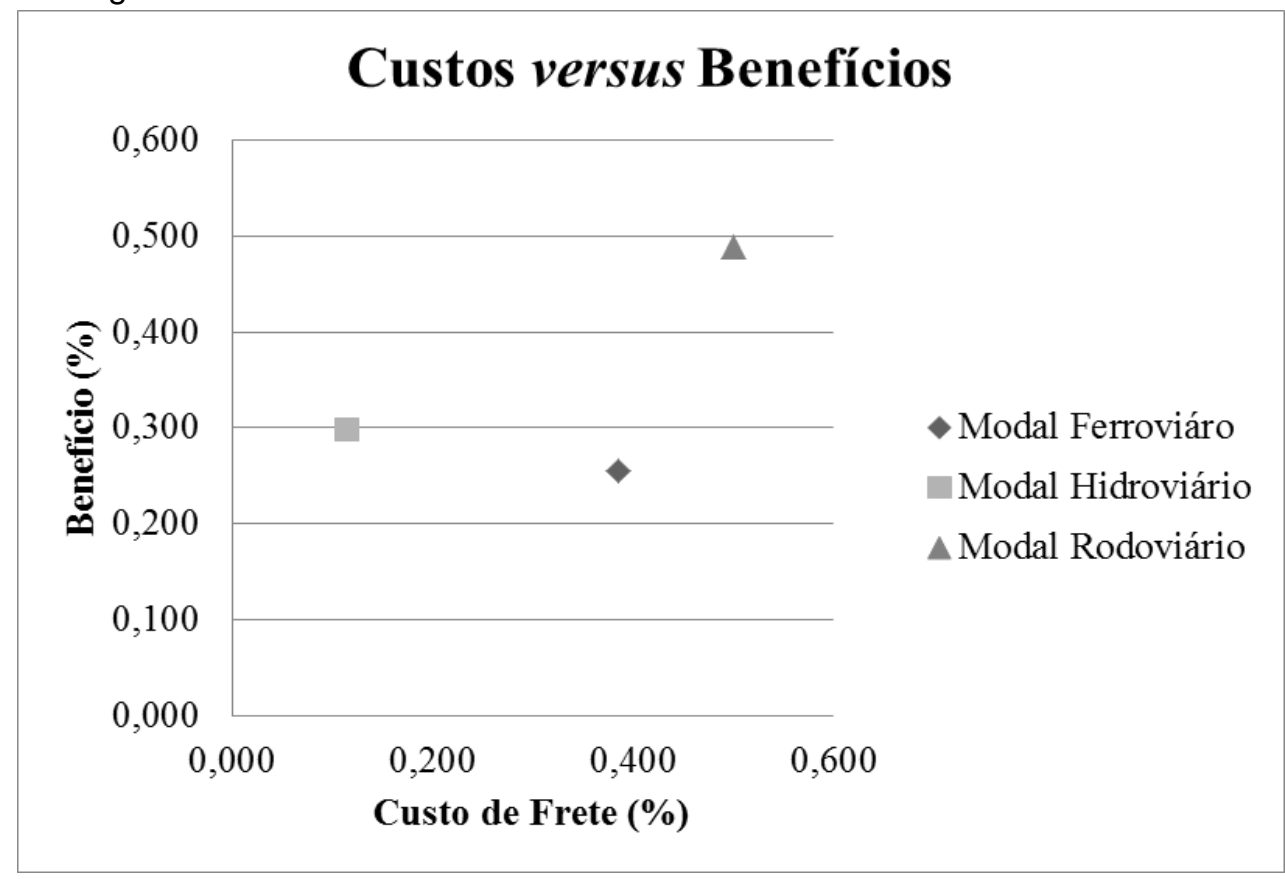

O modo hidroviário apresentou um índice de 0,114 do custo de frete e benefícios de 0,299 correspondentes às variáveis operacionais logísticas; o modo ferroviário apresenta $o$ índice de frete de 0,386 e os benefícios gerados calculados foram de 0,253 , enquanto que o sistema rodoviário possui $0,500 \%$ de custo de frete e as vantagens projetam-se em $0,448 \%$.

O Modal Rodoviário é o sistema de transportes com maior custo de frete em contrapartida possui bons benefícios gerados, o modo ferroviário tem frete menor que o rodoviário, porém, os benefícios são menores do que este modal e por fim, as hidrovias são os sistemas de transportes com custos mais baixos, mas também tem benefícios menores que o rodoviário, apenas ganhando em benefícios quando comparado ao modal ferroviário.

Em relação ao transporte de grãos, por exemplo, o modo hidroviário possui frete mais barato para distâncias longas quando comparado ao modo rodoviário, este que tem custo de transporte mais caro. A vantagem do modal hidroviário está relacionada com a grande capacidade em movimentar produtos que se rateiam os custos fixos pela tonelagem transportada, em que estes gastos se tornam maiores nos modos ferroviário e rodoviário, respectivamente (PRATER et al., 2013).

O modal hidroviário destaca-se como um dos que mais benefícios possuem, com custos mínimos, quando comparados com os modos rodoviário e ferroviário. Neste aspecto, o modo hidroviário é recomendado para produtos com valores 
agregados mínimos e também em grandes volumes para que os custos sejam proporcionais ao carregamento (PIRES e SANTOS, 2013).

O sistema rodoviário pode influenciar outras cadeias produtivas e, por consequência, aspectos sociais também podem ser beneficiados por este modal, por exemplo, construções de rodovias que atraem mão de obra direta e indireta pelo desenvolvimento que a mesma trás localmente (ELLER et al., 2011).

Porém, Pereira e Lessa (2011) ressalta que o modal rodoviário é o mais utilizado devido a fatores geomorfológicos, à distribuição da população pelo país, além dos incentivos o uso deste modo. Ainda existem nebulosidades de informações em relação às rodovias brasileiras, tanto em Municípios, Estados e na esfera Federal, mas sabe-se que a manutenção das vias é precária, com problemas de gestão por parte do setor público, além da utilização de veículos com vida útil ultrapassada.

O mesmo autor argumenta que a malha ferroviária do país pode ser considerada baixa cuja principal desvantagem está na baixa integração entre as linhas férreas, bem como, considera-se que nem todo trecho é considerado potencialmente econômico. Torna-se difícil as ferrovias conseguirem concorrer com as rodovias, justamente pelo fato daquelas buscarem atender às suas próprias demandas e não em ofertar serviços de transportes como é corriqueiro ao sistema rodoviário (PEREIRA e LESSA, 2011).

Além destes aspectos, outras características fazem com que o modal rodoviário seja preferível ao ferroviário, dentre estas estão nos custos de frete próximos do sistema rodoviário em circunstâncias predeterminadas, cuja principal influência está no monopólio executados pelas empresas ferroviárias (MARCHETTI e FERREIRA, 2012).

Com esta perspectiva, de acordo com Pereira e Lessa (2011) existem grupos de pressões que fomentam o uso excessivo do modal rodoviário para que cadeias produtivas correlatas possam ser beneficiadas com estímulo econômico. Assim, observa-se que o modal rodoviário pode estimular o sistema econômico do país e promover sistemas produtivos que se beneficiam direta ou indiretamente deste sistema de transportes.

Neste aspecto, pode-se entender que o modal rodoviário tende a serem muito utilizados devido suas características operacionais, mesmo que os custos de fretes sejam elevados, pois os demais modos não fornecem serviços que garantam melhor benefício quando comparado com o modal rodoviário.

\section{CONSIDERAÇÕES FINAIS}

O objetivo desta pesquisa foi estabelecer um modelo de decisão para verificar qual a melhor opção de transporte para o transporte de grãos no Brasil considerando fatores como capacidade, flexibilidade, velocidade, disponibilidade e frequência. $O$ 
trabalho estabeleceu como caso para estudo do modelo a região centro-oeste brasileira e mais especificamente o estado de Mato Grosso do Sul.

Os resultados da pesquisa utilizando o modelo de decisão hierárquica da metodologia AHP indicaram que o modal rodoviário é a melhor opção $(0,488)$ entre as três disponíveis na região, sendo o principal modal a ser utilizado quando se considera os custos e o atendimento aos cinco fatores físicos de transporte considerados.

Entende-se que o modal rodoviário corresponde ao sistema de transporte mais utilizado atualmente, visto que é o modal que mais se beneficia das variáveis disponibilidade, confiabilidade e frequência. $O$ modal hidroviário apresenta benefícios em primeiro lugar nos critérios capacidade e velocidade e o sistema ferroviário apresenta sempre colocações intermediárias entre os modos rodoviário e hidroviário.

Os gestores logísticos da movimentação de grãos deveriam levar em consideração informações operacionais e os custos de frete quando forem necessárias as escolhas de modos de transportes ao realizarem estas comparações pela Análise Custo versus Benefício e decidirem pelo sistema que mais se adequa às condições do ambiente analisado.

\section{REFERÊNCIAS}

ACZÉL, J.; SAATY, T. L. Procedures for synthesizing ratio judgements. Journal of Mathematical Psychology, v. 27, n. 1, p.93-102, 1983. http://dx.doi.org/10.1016/00222496(83)90028-7

AGUARÓN, J.; MORENO-JIMÉNEZ, J. M. The geometric consistency index: Approximated thresholds. European Journal of Operational Research, v. 147, n. 1, p. 137-145, 2003. http://dx.doi.org/10.1016/S0377-2217(02)00255-2

ARAÚJO, M. J. Fundamentos de agronegócios. 4. ed. São Paulo: Atlas, 2013. 175 p. BALLOU, R. H. Gerenciamento da Cadeia de Suprimentos/Logística Empresarial. 5. ed. Porto Alegre: Bookman, 2006. 616 p.

BASAK, I.; SAATY, T. Group decision making using the analytic hierarchy process.

Mathematical and Computer Modelling, v. 17, n. 4, p. 101-109, 1993. http:// doi:10.1016/0895-7177(93)90179-3

BOWERSOX, D. J.; CLOSS, D. J. Logística empresarial: O processo de integração da cadeia de suprimento. 1. ed. São Paulo: Atlas, 2011. 602 p.

BOWERSOX, D.; CLOSS, D.; COOPER, M. B. Supply chain logistics management. 4. ed. New York, N.Y.: McGraw-Hill Education, 2012. 496 p.

BRANCO, J. E. H.; FILHO, J. V. C.; GAMEIRO, A. H.; MINATEL, M.; MARTA, J. M. C. Desafios para o desenvolvimento da multimodalidade no transporte das safras agrícolas 
pelo corredor centro-oeste sob a ótica dos agentes envolvidos. Revista de Estudos Sociais, v.12, n.23, p.134-161, 2011.

CHOPRA, S.; MEINDL, P. Supply Chain Management. 5. ed. Boston, M.A.: Prentice Hall, 2012. $528 \mathrm{p}$.

COMPANHIA NACIONAL DE ABASTECIMENTO. Acompanhamento da safra brasileira de grãos. Observatório Agrícola, v.2, n.9, p.1-104, 2015.

DULLAERT, W.; ZAMPARINI, L. The impact of lead time reliability in freight transport: A logistics assessment of transport economics findings. Transportation Research Part E: Logistics and Transportation Review, v. 49, n.1, p. 190-200, 2013. http://dx.doi.org/10.1016/j.tre.2012.08.005

DYER, R. F.; FORMAN, E. H. Group decision support with the analytic hierarchy process. Decision Support Systems, v. 8, n. 2, p. 99-124, 1992. http://doi: 1 0.1016/01679236(92)90003-8

DIAS, M. A. Logística, transporte e infraestrutura: Armazenagem, operador logístico, gestão via TI, multimodal. 1. ed. São Paulo: Atlas, 2012. 340 p.

ELLER, R. A. G.; SOUSA JUNIOR, W. C.; CURI, M. L. C. Custos do transporte de carga no Brasil: rodoviário versus ferroviário. Journal of Transport Literature, Manaus, v. 5, n. 1, p. 50-64, 2011.

ENCALADA, J. A. D.; DUHAMEL, F. B. Logistics service characteristics and supply chain priorities for freight management. Academia Revista Latinoamericana de Administración, v.27, n.2, p.236-266, 2014. http://dx.doi.org/10.1108/ARLA-09-2013-0133

FLEURY, P.F. Gestão estratégica do transporte. Revista Tecnologística, n. 82, p. 60-66, 2002.

GOMES, L. F. A. M.; GONZÁLEZ, M. C. A.; CARIGNANO, C. Tomada de decisões em cenários complexos: Introdução aos métodos discretos do apoio multicritério à decisão. 1 . ed. São Paulo: Thomson, 2004. 168 p.

GRAY, R. Behavioural approaches to freight transport modal choice. Transport Reviews, v.2, n.2, p.161-184, 1982. http://dx.doi.org/10.1080/01441648208716491

HOPEWELL, K. The transformation of state-business relations in an emerging economy.

Critical Perspectives on International Business, v.10, n.4, p.291-309, 2014.

http://doi.org/10.1108/cpoib-03-2014-0019

ISHIZAKA, A.; LABIB, A. Review of the main developments in the analytic hierarchy process. Expert Systems with Applications, v.38, n.11, 14336-14345, 2011.

http://doi.org/10.1016/j.eswa.2011.04.143

KUSSANO, M. R.; BATALHA, M. O. Agribusiness logistics costs: Evaluation of Mato Grosso state's soybean export. Gestão \& Produção, v.19, n.3, p.619-632, 2012.

http://doi.org/10.1590/S0104-530X2012000300013 
LEAL JUNIOR, I. C.; D'AGOSTO, M. A. Modal choice for transportation of hazardous materials: The case of land modes of transport of bio-ethanol in Brazil. Journal of Cleaner Production, v.19, n.2-3, p.229-240, 2011. http://doi.org/10.1016/j.jclepro.2010.02.006

MINISTERIO DA AGRICULTURA, PECUÁRIA E ABASTECIMENTO. Projeções do agronegócio: Brasil 2013/2014 a 2023/2024 projeções de longo prazo. Brasilia: MAPA/ACS, 2014. 133 p.

MORALES, P. R. G. D.; D'AGOSTO, M. A.; SOUZA, C. D. R. Optimization network for intermodal transport of soybeans in northern Mato Grosso to the port of Santarém. Journal of Transport Literature, v.7, n.2, p.29-51, 2013. http://doi.org/10.1590/S223810312013000200003

OSAKI, M.; BATALHA, M. O. Optimization model of agricultural production system in grain farms under risk, in Sorriso, Brazil. Agricultural Systems, v.127, n.1, p.178-188, 2014. http://doi.org/10.1016/i.agsy.2014.02.002

PRATER, M. E. et al. Rail market share of grain and oilseed transportation. Journal of the Transportation Research Forum, v. 52, n. 2, p. 127-150, 2013.

PEREIRA, L. A. G.; LESSA, S. N. O processo de planejamento e desenvolvimento do transporte rodoviário no Brasil. Caminhos de Geografia, v. 12, n. 40, 2011.

PIRES, M. J. S.; SANTOS, G. R. Modelo agroexportador, política macroeconômica e a supremacia do mercado: Uma visão do modelo brasileiro de exportação de commodities. Brasília: IPEA, 2013. 38 p.

RADMILOVIĆ, Z.; ZOBENICA, R.; MARAŠ, V. River-sea shipping - competitiveness of various transport technologies. Journal of Transport Geography, v.19, n.6, p.1509-1516, 2011. http://doi.org/10.1016/i.jtrangeo.2011.03.002

REIS, V. Analysis of mode choice variables in short-distance intermodal freight transport using an agent-based model. Transportation Research Part A: Policy and Practice, v. 61, p. 100-120, 2014. http://doi.org/10.1016/i.tra.2014.01.002

REIS, V.; FABIAN MEIER, J.; PACE, G.; PALACIN, R. Rail and multi-modal transport. Research in Transportation Economics, v.41, n.1, p.17-30, 2013. http://doi.org/10.1016/i.retrec.2012.10.005

SAATY, R. W. The analytic hierarchy process: what it is and how it is used. Mathematical Modelling, v.9, n.3-5, p.161-176, 1987. http://doi.org/10.1016/0270-0255(87)90473-8

SAATY, T. L. The analytic hierarchy process: Planning, priority setting, resources allocation. New York, NY: Mcgraw-Hill, 1980. 287 p.

SAATY, T. L. How to make a decision: The analytic hierarchy process. European Journal of Operational Research, v.48, n.1, p.9-26, 1990. http://doi.org/10.1016/0377-2217(90)90057|

SAATY, T. L. Decision making with the analytic hierarchy process. International Journal of Services Sciences, v.1, n.1, p.83-98, 2008. http://doi.org/10.1504/IJSSCI.2008.017590

SOLIMANPUR, M., GHOLAMREZA, M., GHAYOUR, F. Optimum portfolio selection using a hybrid genetic algorithm and analytic hierarchy process. Studies in Economics and Finance, v.32, n.3, p.379-394, 2015. http://doi.org/10.1108/SEF-08-2012-0085 
SOUZA, D.F., MARKOSKI, A. A competitividade logística no Brasil: Um estudo com base na infraestrutura existente. Revista de Administração, v.10, n.17, p.135-144, 2013.

TALIB, F.; RAHMAN, Z. Identification and prioritization of barriers to total quality management implementation in service industry: An analytic hierarchy process approach. The TQM Journal, v.27, n.5, p.591-615, 2015. http://doi.org/10.1108/TQM-11-2013-0122

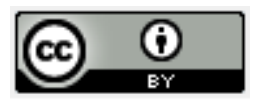

Artigo recebido em 24/10/2015 e aceito para publicação em 03/10/2016 DOI:http://dx.doi.org/ 10.14488/1676-1901.v16i4.2206 